Revue

Revue de l'histoire des religions

de Ihistoire des religions

$1 \mid 2020$

Varia

\title{
Patrick WERLY, Yves Bonnefoy et l'avenir du divin
}

Paris, Hermann (« Savoir lettres »), 2017

\section{François Trémolières}

\section{OpenEdition}

\section{Journals}

Édition électronique

URL : https://journals.openedition.org/rhr/10486

DOI : 10.4000/rhr.10486

ISSN : 2105-2573

\section{Éditeur}

Armand Colin

\section{Édition imprimée}

Date de publication : 1 mars 2020

Pagination : 169-170

ISBN : 978-2-200-93291-6

ISSN : 0035-1423

Référence électronique

François Trémolières, «Patrick WerLy, Yves Bonnefoy et l'avenir du divin », Revue de I'histoire des religions [En ligne], 1 | 2020, mis en ligne le 01 janvier 2021, consulté le 05 janvier 2023. URL : http:// journals.openedition.org/rhr/10486 ; DOI : https://doi.org/10.4000/rhr.10486

Ce document a été généré automatiquement le 5 janvier 2023

Tous droits réservés 


\title{
Patrick WeRLY, Yves Bonnefoy et l'avenir du divin
}

Paris, Hermann (« Savoir lettres »), 2017

\author{
François Trémolières
}

\section{RÉFÉRENCE}

Patrick WERLY, Yves Bonnefoy et l'avenir du divin, Paris, Hermann (« Savoir lettres »), 2017, $23 \mathrm{~cm}, 423$ p., $38 €$, ISBN 978-2-7056-9337-4.

1 Poète, titulaire de la chaire d'Études comparées de la fonction poétique au Collège de France, Yves Bonnefoy (1923-2016) fut aussi, entre autres, le fondateur de la collection Idées et Recherches chez Flammarion (l'éditeur notamment de l'Essai sur le mysticisme grec de Dario Sabbatucci, ou encore d'Henry Corbin) et le maitre d'œuvre du Dictionnaire des mythologies, paru l'année même de son élection au Collège (1981) : à ce titre au moins il entretint une relation privilégiée avec ce qu'il appelait lui-même «l'école française » d'histoire des religions, à savoir principalement les membres de la section Sciences religieuses de l'École pratique des hautes études. Cela suffirait sans doute à signaler le présent ouvrage aux lecteurs de la Revue de l'histoire des religions mais il va de soi que P. Werly ne s'en tient pas là. C'est bien au poète qu'il s'intéresse, et au penseur de la poésie. Son hypothèse de départ est « qu'il n'y a pas d'impensé religieux » dans la poésie d'Yves Bonnefoy (pas non plus de « crypto-christianisme »), « que la religion y a été pensée, pour mettre en relief à la fois sa limitation idéologique, discursive, et l'expérience authentique de la transcendance » - qui serait le fait de la poésie. D'où le dialogue inévitable de «la poésie avec la pensée religieuse » (première partie). À la condition d'entendre par poésie une forme de connaissance, et aussi d'engagement.

2 Ce dialogue va jusqu'à l'intime du poème et de la méditation du poème, ou du poétique, comme le montre (deuxième partie) la reprise incessante par Bonnefoy du mythe de Déméter et Coré, lui-même lié aux Mystères d'Éleusis. La poésie " consciente de soi » 
n'est pas la gnose, même si elle en a la tentation, elle n'est pas non plus la mystique entendue ici dans une acceptation qui doit beaucoup, d'après l'auteur, à Sabbatucci.

Le Dictionnaire des mythologies, ce qu'affirmait son titre, faisait un partage très net entre les religions du salut, dont il avait décidé de ne pas traiter, et les autres. P. Werly suit le même mouvement, étudiant séparément (troisième partie) le rapport du poète au christianisme. Lecteur précoce de Kierkegaard (auquel il consacra, sous la direction de Jean Wahl, un mémoire de maîtrise, non conservé), ami de Jouve, exégète de Baudelaire à partir duquel il avait posé le diagnostic que la poésie moderne eut à se définir « dans le même instant, par le christianisme et contre lui », Bonnefoy a travaillé le lexique chrétien et lui a fait des emprunts très informés, dont celui du mot «Dieu " (emplois qui ont suscité d'abondantes exégèses dans la très fournie littérature critique sur Bonnefoy). C'est un "nom propre » qui désigne un possible de la langue : «ce qui du monde demeure transcendant pour le langage ». Un « Dieu à naître » et non un Dieu origine ; à venir, mais d'une venue qui n'est autre que le présent de son attente.

4 Aussi la dernière partie est-elle consacrée à « la poésie comme reprise : porter le stade religieux au stade poétique ». La terminologie est kierkegaardienne. Mais le «stade religieux » n'est plus le stade ultime. Il s'agit bien, comme chez Kierkegaard, de la «finitude du temps ». Mais c'est la poésie, non la religion, qui l'assumerait tout à fait. De plus en plus nettement la poésie de Bonnefoy s'est faite reprise, répétition, «réparation» (Michèle Finck). Elle s'est aussi rapprochée de l'enfance. Il y a une « herméneutique de la reprise » qui fait du poème une alternative heureuse au mythe, offre un autre rapport au temps et à l'origine.

5 L'ouvrage de P. Werly, dont il était impossible de restituer la richesse, se signale par une ampleur de vue rare chez les "littéraires". Sans doute la doit-il pour partie à l'exigeante fidélité à son modèle, lui-même engagé dans une quête encyclopédique, et au dialogue qu'il avait noué avec lui, dont témoignent discrètement certaines pages. L'opposition qu'il signale en passant entre la "somme » et le " projet » distingue sans doute le commentateur du poète et indique par là le risque du commentaire - mais jamais ici la «somme » ne vient étouffer le « projet».

\section{AUTEURS}

\section{FRANÇOIS TRÉMOLIÈRES}

Université Rennes 2 / CELLAM. 